\title{
A New Glycine soja Germplasm Accession with Green Seed-coat Color
}

\author{
Jeong-Dong Lee'), Yong-Hwi Yoon'), Il-Kyung Chung' ${ }^{2)}$, Soon-Ki Park ${ }^{1)}$ and Young-Hyun Hwang*1) \\ 1) Division of Plant Biosciences, College of Agriculture and Life Sciences, Kyungpook National University, Daegu 702-701, Korea \\ 2) Faculty of Life Resources, Catholic University of Daegu, Kyungsan, Kyungbuk 712-702, Korea
}

\begin{abstract}
Wild soybean (Glycine soja) is a useful genetic resource for broadening the genetic background of cultivated soybean. We selected a wild type soybean line showing a unique character consisting of a green seed-coat color at Yeongchun in Korea 1996 and designated it as KLG10084. The objectives of the present study were as follows; (1) to evaluate the agronomic characters of KLG10084 by comparing them to those of other wildtype accessions and cultivars, and (2) to evaluate the possibility of improving the seed-coat color in an interspecific cross of $G$. $\max \times G$. soja. The major agronomic traits of KLG10084 were investigated and a genetic relationship was analyzed by comparing it to wild soybean (G. soja) and soybean cultivars (G. max) using the RAPD technique. KLG10084 was similar to IT184256, one of the $G$. soja accessions tested, that was known as a wild soybean exhibiting typical wild-type characters in stem diameter, pod size at maturity, seed size, hard seed and viny growth habit. A cluster analysis using UPGMA suggested that KLG10084 belonged to the group of wild soybean. It strongly indicated that the KLG10084 line corresponded to an accession of G. soja showing a green seed-coat color, based on morphological and RAPD analysis. The populations were generated by crossing KLG10084 with two different G. max cultivars, 'Sobaegnamulkong' and 'Eunhakong', and backcrossing it to the G. $\max$ parent to obtain $\mathrm{BC}_{0}$ to $\mathrm{BC}_{3}$ populations. The seed-coat color was evaluated on the populations representing each generation. The percentage of acceptable seed-coat color was $74 \%$ in the $\mathrm{BC}_{0} \mathrm{~F}_{2}, 90 \%$ in the $\mathrm{BC}_{1} \mathrm{~F}_{2}$ and $97 \%$ in the $\mathrm{BC}_{2} \mathrm{~F}_{2}$ generations, and approximately $100 \%$ in the $\mathrm{BC}_{3} \mathrm{~F}_{2}$ generation in the population of Eunhakong $\times \mathrm{KLG10084}$. These results indicated that a single backcross is required to recover a commercially desirable seed-coat color in a population derived from an interspecific cross of G. $\max \times$ G. soja when KLG10084 is used as a G. soja parent. Therefore, KLG10084 was considered to be a valuable gene source in overcoming the seed-coat color in interspecific crosses and was particularly useful for shortening soybean breeding programs by reducing the number of backcrosses that are required.
\end{abstract}

Key Words: Glycine max, Glycine soja, inerspecific cross, RAPDs, seed-coat color.

\section{Introduction}

Plant genetic resources (PGR) have contributed to human life and civilization. Therefore, through using, improved PGR for more suitable agriculture aimed at many purposed may provide various social and economic benefits, prosperity, environmental protection, health, etc. As a result, conservation in a genebank, evaluation and use of the PGR for genetic materials, international collaboration and networking are very important (Watanabe and Iwanaga 1999).

Interspecific crossing has been one of the valuable breeding methods for the development of a new variety through the introduction of useful genes. Wild relatives of crops have been used as a source of favorable useful agronomic traits, such as resistance to diseases, insects and nematodes, as well as increase of yield (Harlan 1976). However, the major constraints on the use of wild relatives in breeding

Communicated by K.N. Watanabe

Received February 9, 2004. Accepted August 20, 2004.

*Corresponding author (e-mail: hwangyh@knu.ac.kr) programs include technical difficulties in crossing, complete or partial sterility of resulting hybrids and lack of information on genetic pedigree. Furthermore, progenies display unfavorable agronomic characters such as low yield, poor flavor, etc. (Hawkes 1977). Presently, due to the improvement of technology, the use of wild species is less difficult (Watanabe et al. 1995, Chung and Kim 1990).

The genus Glycine Willd. has been currently classified into two subgenera, Glycine and Soja (Moench) F.J. Herm (Hymowitz and Newell 1981). The subgenus Soja includes the cultivated soybean, Glycine $\max ($ L.) Merrill and wild soybean G. soja Sieb, and Zucc. G. soja is widely distributed in Korea, China, Japan, Taiwan and on a belt of Siberia adjacent of northern China (Hymowitz and Singh 1987). In Korea, the species grows naturally on riverbanks, on roadsides and at sites with a patchy distribution. Some researchers identified the distribution of the genetic diversity of G. soja in Korea. Yu and Kiang (1993) examined 35 loci in 17 isozymes and trypsin inhibitors and reported a surprisingly high variation, suggesting that Korea is likely to be one of the major soybean gene centers. An analysis of genetic 
variation using RAPD and isozyme techniques also indicated that overall genetic variation among the wild soybeans was greater than that of the cultivated soybeans. The genetic similarity was averaged at $89 \%$ among the tested 38 Soja accessions. By cluster analysis, wild soybean germplasm was separated from the cultivated germplasm at a similarity level of approximately 83\% (Park et al. 1995).

$G$. soja has not been used widely in soybean breeding programs because of its undesirable traits for cultivation, including low yield, viny growth habit, lodging, shattering, absence of defoliation at maturity, poor seed quality and absence of a yellow seed-coat color (Gai et al. 1981). Some researchers, however, were able to overcome undesirable characters and succeeded in the development of genetic variation from the interspecific cross of $G$. $\max \times G$. soja (Gai et al. 1981, Carpenter and Fehr 1986, LeRoy et al. 1991a, 1991b, Yang et al. 1994). We selected a wild type soybean line designated as KLG10084 showed a green seed-coat color at Yeongchen in the southern area of Korea in 1996. We carried out a characterization of the major agronomic traits and analysis of the genetic relationship by comparing it to soybean cultivars. The objectives of this study were firstly, to evaluate KLG10084's agronomic characters focusing on the seed-coat color and, secondly, the possibility of using it in soybean breeding programs for the improvement of the seed-coat color in a population derived from an interspecific cross between $G$. $\max \times G$. soja.

\section{Materials and Methods}

\section{Genetic materials}

Four improved varieties of G. $\max$ (Pungsannamulkong, Sobaegnamulkong, Eunhakong and Hwangkeumkong), four accessions of G. soja (IT182942, IT184172, T184178 and IT18425) and KLG0084 were used in this experiment. Eunhakong was developed at the National Yeongnam Agricultural Experiment Station in Korea. Two major characters of the four cultivated varieties and five wild soybean accessions are shown in Table 1. We selected three lines (IT184256, KLG10084 and Eunhakong) for a detailed evaluation of agronomic traits including plant height, number of branches, number of nodes, stem diameter, pod size at maturity, seed weight, seed-coat color, flower color, pubescence color, water absorption of seed after 24 hours and growth habit.

\section{$D N A$ extraction and $R A P D$}

Soybean genomic DNA was extracted from individual plants at the first node stage according to the method of Keim et al. (1988). The PCR mixtures $(50 \mu \mathrm{l})$ contained; 20 ng of genomic DNA, $50 \mathrm{mM}$ of $\mathrm{KCl}, 10 \mathrm{mM}$ of Tris- $\mathrm{HCl}, 2$ $\mathrm{mM}$ of $\mathrm{MgCl}_{2}, 0.01 \%$ of gelatin, $0.1 \%$ of triton X-100, 0.2 $\mathrm{mM}$ of each dNTP mixture, $0.2 \mu \mathrm{M}$ of primer, and a 1.25 unit of Taq DNA polymerase (TaKaRa, Japan). Each reaction mixture was overlaid with $20 \mu \mathrm{l}$ of mineral oil to prevent evaporation. The reactions were performed on a MJ miniCycler (Thermohybaid, USA). The cycling profile for the reaction was as follows: 45 cycles of $60-\mathrm{sec}$ denaturation at $94^{\circ} \mathrm{C}$, 60 -sec annealing at $37^{\circ} \mathrm{C}, 120$-sec extension at $72^{\circ} \mathrm{C}$, with a final extension of $10 \mathrm{~min}$, at $72^{\circ} \mathrm{C}$. The PCR products were separated by agarose $(1.2 \%)$ gel electrophoresis. Seventeenselected 10-base random primers (Operon Technologies) were used in this experiment.

\section{Data analyses}

Each amplified fragment was scored as present $(0)$ or absent (1). To compare the polymorphism, all the polymorphic and monomorphic fragments were included in the analyses. Genetic similarity was based on the calculation of $2 \mathrm{Nxy} / \mathrm{Nx}+\mathrm{Ny}$, where Nxy denotes the number of shared bands between two individuals ( $\mathrm{x}$ and $\mathrm{y}$ ) and $\mathrm{Nx}$ and $\mathrm{Ny}$ denote the number of scored bands in the individuals $\mathrm{x}$ and $\mathrm{y}$, respectively (Nei and Li 1979). Cluster analyses were based on similar matrices using the unweighted pair group method arithmetic average (UPGMA). Clustering was performed using the software program NTSYS-PC system version 2.02 (Exeter Soft-ware Co.).

\section{Frequency distribution of acceptable seed-coat color depending on the backcrosses}

Eunhakong and Sobaegnamulkong were selected for their high yield, good agronomic characters and yellow seedcoat color, and KLG10084 for the green seed-coat color as

Table 1. G. soja and G. max varieties, accessions and lines used in the present study

\begin{tabular}{llcl}
\hline \hline \multirow{6}{*}{ G. soja } & Accessions & 100-seed weight $(\mathrm{g})^{1)}$ & Seed-coat color \\
& IT182942 & $2.5 \mathrm{e}$ & Non-glossy black \\
& IT184172 & $2.0 \mathrm{e}$ & Non-glossy black \\
& IT184178 & $5.4 \mathrm{~d}$ & Black \\
& IT184256 & $2.4 \mathrm{e}$ & Non-glossy black \\
& KLG10084 & $2.6 \mathrm{e}$ & Green \\
\hline \multirow{6}{*}{ max } & Eunhakong & $13.4 \mathrm{~b}$ & Yellow \\
& Sobaegnamulkong & $10.3 \mathrm{c}$ & Yellow \\
& Pungsannamulkong & $11.0 \mathrm{c}$ & Yellow \\
& Hwangkeumkong & $25.2 \mathrm{a}$ & Yellow \\
\hline
\end{tabular}

1) Means with the same letter within a column are not significantly different at the $5 \%$ level of DMRT. 
the G. soja parents. The interspecific crosses, Eunhakong $\times$ KLG10084 and Sobaegnamulkong $\times$ KLG10084 were performed in the summer of 1997 in an experimental field at Kyungpook National University (KNU), giving rise to populations. In the subsequent backcrossing program, the G. max cultivars (Eunhakong and Sobaegnamulkong) were used as pollen donors. No selection among the $\mathrm{BCnF}_{1}$ plants was practiced for qualitative or quantitative characters during backcrossing. $\mathrm{F}_{2}$ and $\mathrm{BC}_{1} \mathrm{~F}_{1}$ were obtained from the $\mathrm{F}_{1}$ plants in the field at $\mathrm{KNU}$ in $1998 . \mathrm{BC}_{1} \mathrm{~F}_{2}$ and $\mathrm{BC}_{2} \mathrm{~F}_{1}$ seeds were harvested from the $\mathrm{BC}_{1} \mathrm{~F}_{1}$ plants in 1999. $\mathrm{BC}_{2} \mathrm{~F}_{2}$ and $\mathrm{BC}_{3} \mathrm{~F}_{1}$ seeds were obtained from the $\mathrm{BC}_{2} \mathrm{~F}_{1}$ plants in 2000 . The $\mathrm{BC}_{3} \mathrm{~F}_{2}$ seeds were obtained from the $\mathrm{BC}_{3} \mathrm{~F}_{1}$ plants at the KNU nursery from February to June in 2001. On June 16 2001, $\mathrm{F}_{2}$ and $\mathrm{BCnF}_{2}$ seeds, 300 each were planted, respectively. Plots consisted of single-plant hills sown in a grid of $60 \times 15 \mathrm{~cm}$. Acceptable seed-coat color was evaluated depending on the number of backcrosses.

\section{Results and Discussion}

\section{Comparison of agronomic characters}

Table 2 shows a comparison of the characters among the three lines. The value of the plant height of KLG10084 was intermediate between that of the two lines, being lower than that of IT184256 and higher than that of Eunhakong. Among the following characters, stem diameter, pod size, seed weight, 100-seed weight, flower and pubescence color, water absorbance rate and growth habit of KLG10084 were significantly similar to those of IT184256, which was investigated in this study as a wild type soybean (Fig. 1 and Table 2). In contrast to the wild type soybean, KLG10084 showed a green seed coat color. Broich and Palmer (1980, 1981) classified cultivars (193 lines) and wild soybeans (366 lines) into two groups, G. max and G. soja, based on cluster analysis of the frequency of ten loci and analysis of the morphological characters.

Yang et al. (1993) reported major agronomic characters from $674 \mathrm{G}$. soja lines which had been collected in Jilin
Province, China. Approximately $96 \%$ of the tested lines exhibited a black seed coat. The ranges of 100 -seed weight and plant height were $0.5-3.0 \mathrm{~g}$ and $0.48-2.21 \mathrm{~m}$, respectively. The means of the 100-seed weight, plant height and days to maturity were $1.6 \mathrm{~g}, 221 \mathrm{~cm}$ and 127.1 days, respectively. These values were similar to the results reported by Kim et al. (2003) for the Korean G. soja germplasm accessions, in
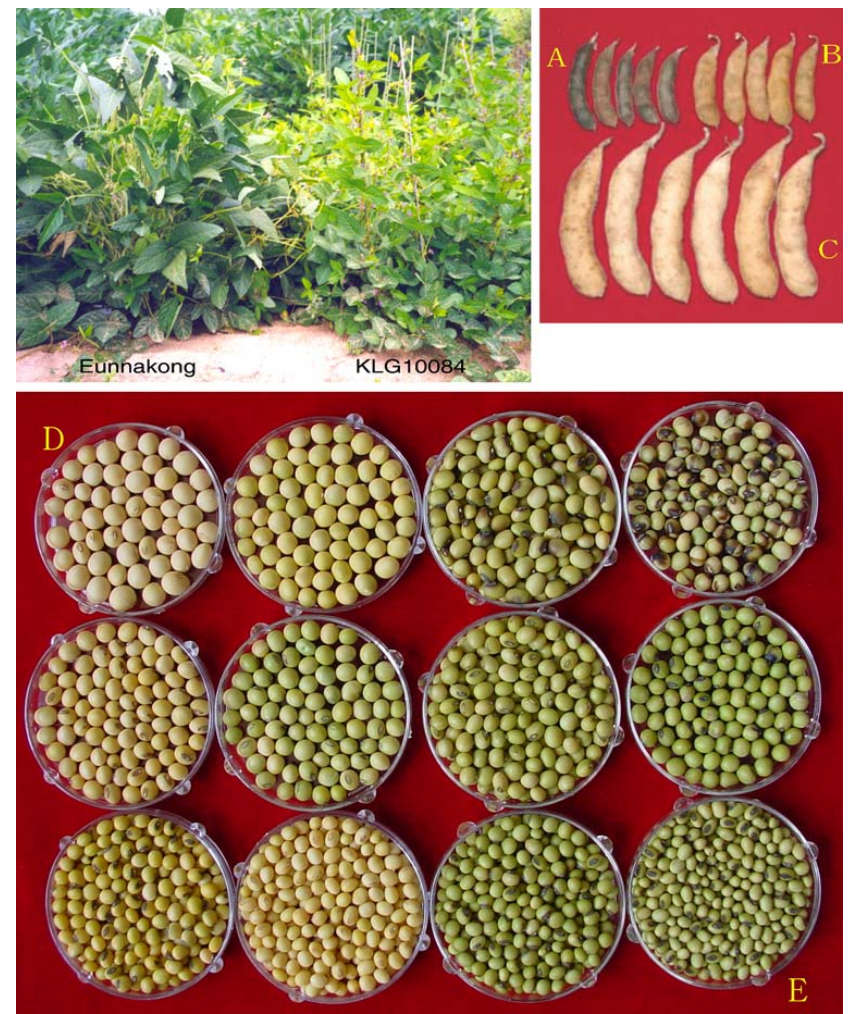

Fig. 1. Plant and pod shape of parents and various shapes of $\mathrm{F}_{2: 3}$ seeds in the cross Eunhakong $\times$ KLG10084. Pod shape of IT184256 (A), KLG10084 (B) and Eunhakong (C). Seed shape of Eunhakong (D: yellow seed-coat color, $11.6 \mathrm{~g}$ per 100 -seed), KLG10084 (E: green seed-coat color, $2.4 \mathrm{~g}$ per 100-seed) and $\mathrm{F}_{2: 3}$ lines.

Table 2. Comparison of characters of wild type soybean line with green seed-coat among Soja lines

\begin{tabular}{lccc}
\hline \hline Characters & IT184256 (G. soja $)$ & KLG100841) & Eunhakong $(G$. max $)$ \\
\hline Plant height $(\mathrm{cm})$ & $110.6 \pm 12.7$ & $74.0 \pm 9.6$ & $52.1 \pm 3.6$ \\
No. of branches & $12.2 \pm 0.9$ & $8.4 \pm 0.8$ & $9.0 \pm 0.4$ \\
No. of nodes & $17.1 \pm 1.0$ & $20.4 \pm 1.0$ & $14.1 \pm 0.6$ \\
No. of pods per plant & $290.0 \pm 8.8$ & $155.4 \pm 12.1$ & $116.2 \pm 11.8$ \\
Stem diameter $(\mathrm{mm})$ & $2.0 \pm 0.2$ & $2.7 \pm 0.2$ & $10.2 \pm 0.3$ \\
3-seeded pod length $(\mathrm{mm})$ & $22.0 \pm 0.3$ & $22.8 \pm 0.3$ & $41.3 \pm 0.8$ \\
3-seeded pod width $(\mathrm{mm})$ & $5.5 \pm 0.3$ & $5.0 \pm 0.1$ & $7.5 \pm 0.2$ \\
100-seed weight $(\mathrm{g})$ & $2.4 \pm 0.1$ & $2.6 \pm 0.1$ & $11.6 \pm 0.1$ \\
Seed-coat color & Non-glossy black & Green & Yellow \\
Flower color & Purple & Purple & Purple \\
Pubescence color & Tawny & Tawny & Gray \\
Water absorption after 24 hours $(\%)$ & $12.6 \pm 0.2$ & $12.3 \pm 0.2$ & $130.3 \pm 0.5$ \\
Growth habit & Viny & Viny & Erect \\
\hline
\end{tabular}

1) KLG10084 : a wild type soybean line used as one of the parents in the experiments. 
which 100 -seed weight ranged from 1.2 to $2.9 \mathrm{~g}$ and the plant height from 0.69 to $2.14 \mathrm{~m}$. Thus, the results of the morphological analysis compared to those of other researchers indicated that KLG10084 displayed typical characters of the wild soybean, G. soja, except for the seed-coat color (Fig. 1 and Table 2).

\section{RAPD profiles and genetic distance}

The genetic variations and relationships among nine soybean varieties, accessions and lines of $G$. max and $G$. soja were investigated using RAPD analysis. Seventeenselected primers yielded 119 fragments of which 40 fragments were polymorphic (33.6\%). The 40 bands that showed polymorphism were used for calculating genetic similarities according to the method of Nei and Li (Nei and Li 1979). The dissimilarity value (genetic distance, 1-F) of the materials ranged for 0.034 between IT184172 and IT182942, up to 0.211 between KLG10084 and Sobaegnamulkong. The average value was approximately 0.140 . KLG10084 showed the highest value in dissimilarity (genetic distance, 1-F) to Sobaegnamulkong, compared to the other materials. However, it was more similar to IT184172 and IT184292 that belonged to the group of $G$. soja. Furthermore, a cluster analysis using UPGMA suggested that KLG10084 belonged to the group of wild soybeans (Fig. 2), indicating that KLG10084 belonged to the G. soja group which was obviously different from G. max based on the UPGMA dendrogram (Fig. 2).

\section{Frequency of seed-coat color depending on the number of backcrosses}

It is important to collect and evaluate new germplasm accessions for increasing breeding efficiency. Although a wild type soybean such as $G$. soja may be a source of useful genetic variability, it shows many undesirable traits, as mentioned in the introduction. The color of the seed coat would be one of the invaluable characters because of the apparent relationship between the seed-coat color and hardness of seed. If seeds contain the black pigment, it can be expected that they would be hard seeds in the cross $G . \max \times G$. soja (Ting 1946, Woodworth 1933).

The frequency of yellow, green and an acceptable seedcoat color (green + yellow) was evaluated in the population that was derived from two interspecific crosses. The frequency was significantly correlated with the number of backcrosses as shown in Table 3. In the case of Eunhakong

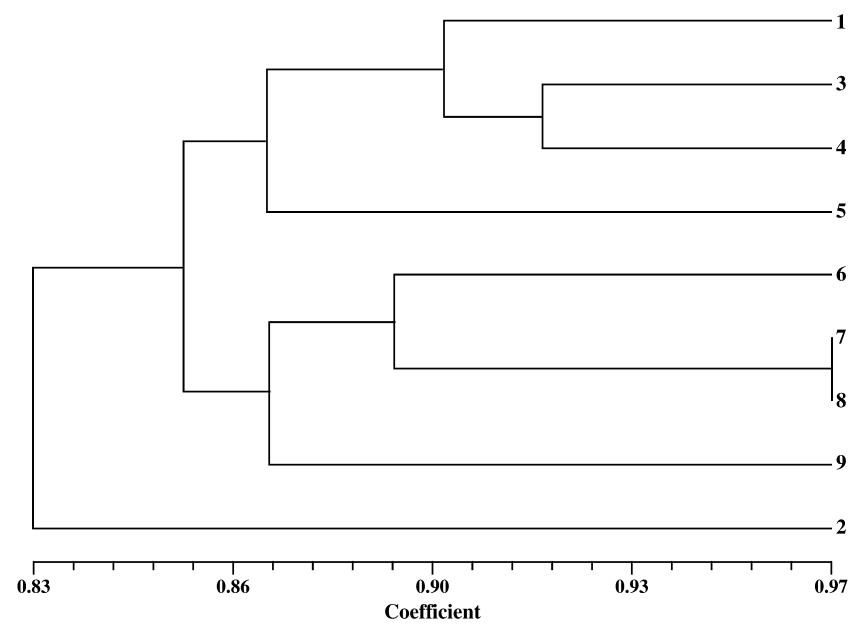

Fig. 2. Dendrogram of G. max and G. soja generated by UPGMA cluster analysis. G. max: Pungsannamulkong (1), Sobaegnamulkong (2), Eunhakong (3), Hwangkeumkong (4), G. soja: IT187178 (5), IT 184256 (6), IT184292 (7), IT184172 (8), KLG10084 (9).

$\times$ KLG10084, the proportion of green and yellow seed-coats was $45.3 \%$ and $29.0 \%$, respectively in the $F_{2}$ population. The acceptable seed-coat color rate amounted to approximately $90 \%$ in the $\mathrm{BC}_{1} \mathrm{~F}_{2}$ population of Eunhakong $\times$ KLG10084 and thereafter, the value increased to $99.6 \%$ in the $\mathrm{BC}_{3} \mathrm{~F}_{2}$ population. In the $\mathrm{F}_{2}$ population of Sobaegnamulkong $\times$ KLG10084, the acceptable seed-coat color rate (45.7\%) was somewhat lower than that in the $\mathrm{F}_{2}$ population of Eunhakong $\times \mathrm{KLG} 10084$, but similar to that in the $\mathrm{BC}_{3} \mathrm{~F}_{2}$ population. It is interesting to note that the recovery frequency of the yellow and green seed-coat color in the present study was different among the cross-combinations, namely $74.3 \%$ in the $F_{2}$ for Eunhakong $\times$ KLG10084 and $45.7 \%$ in the $F_{2}$ for Sobaegnamulkong $\times$ KLG10084. This reflects the genetic difference between parents in the number of loci that control seed pigmentation.

The frequency distribution of the seed-coat color was in the following order; green, yellow, black and brown in the $F_{2}$ population, derived from the interspecific cross between G. max with a yellow color and G. soja (Ting 1946). After a backcross was performed, however, the frequency of the lines homogeneous to the yellow seed-coat generally increased depending on the number of backcrosses. A study conducted by Gai et al. (1981) showed that the frequency of the yellow seed-coat color was $12.3 \%$ in the $\mathrm{F}_{2}, 48.6 \%$ in the

Table 3. Frequency distribution of acceptable seed-coat color depending on the number of backcrosses in two interspecific crosses in Glycine spp

\begin{tabular}{|c|c|c|c|c|c|c|c|}
\hline & \multirow{3}{*}{$\begin{array}{l}\text { No. of total } \\
\text { lines tested }\end{array}$} & \multicolumn{3}{|c|}{ Eunhakong $\times$ KLG10084 } & \multicolumn{3}{|c|}{ Sobaegnamulkong $\times$ KLG10084 } \\
\hline & & \multicolumn{3}{|c|}{ No. of selected acceptable lines } & \multicolumn{3}{|c|}{ No. of selected acceptable lines } \\
\hline & & Total & Green & Yellow & Total & Green & Yellow \\
\hline $\mathrm{BC}_{0} \mathrm{~F}_{2}$ & $300(100)^{1)}$ & $222(74.3)$ & $135(45.3)$ & $87(29.0)$ & $137(45.7)$ & $98(32.7)$ & $39(13.0)$ \\
\hline $\mathrm{BC}_{1} \mathrm{~F}_{2}$ & $300(100)$ & $270(90.4)$ & $54(18.0)$ & $217(72.4)$ & $191(63.9)$ & $88(29.5)$ & $103(34.4)$ \\
\hline $\mathrm{BC}_{2} \mathrm{~F}_{2}$ & $300(100)$ & $291(97.3)$ & $8(2.9)$ & $283(94.4)$ & $246(82.0)$ & $84(28.3)$ & $161(53.7)$ \\
\hline $\mathrm{BC}_{3} \mathrm{~F}_{2}$ & $300(100)$ & $298(99.6)$ & $1(0.3)$ & $297(99.3)$ & $297(99.4)$ & $3(1.2)$ & $294(98.2)$ \\
\hline
\end{tabular}

1) The figures in the parentheses indicate the percentages of total and selected acceptable lines with each seed-coat color. 
$\mathrm{BC}_{1} \mathrm{~F}_{2}, 61.8 \%$ in the $\mathrm{BC}_{2} \mathrm{~F}_{2}$ and $74.5 \%$ in the $\mathrm{BC}_{3} \mathrm{~F}_{2}$ populations for the cross PI 424001(G. soja) $\times$ Amsoy 71(G. max). Although there was a difference in the yellow seed-coat color rate as a cross-combination in our study, the results showed a similar recovery rate in the $\mathrm{BC}_{1} \mathrm{~F}_{2}$ population using $\mathrm{KLG} 10084$, compared to the $\mathrm{BC}_{3} \mathrm{~F}_{2}$ population in an analysis conducted by Gai et al. (1981). Thus, we were able to overcome the undesirable seed color by performing a single backcross.

Wild soybean $G$. soja including KLG10084 has considered being the progenitor of G. max cultivars (Hymowitz and Singh 1987). These two species show the same number of chromosomes and can be intercrossed freely to produce fertile offspring. Therefore, wild soybean has been estimated to be a useful source for broadening the genetic diversity of cultivated soybean. Some characters in G. soja such as pest and disease resistance, high protein content, and a small seed-size for sprout, can be and have been, in some instances, transferred to the G. max cultivars (Gai et al. 1981, Carpenter and Fehr 1986, LeRoy et al. 1991a, 1991b). Particularly, seed-coat color is one of the considerations for the development of special cultivars for producing sprouts, especially in Korea. For this reason, KLG10084 could be evaluated as a valuable gene source for overcoming the seed-coat color in an interspecific cross between G. max and $G$. soja. And it will be particularly useful for shortening soybean breeding programs by reducing the number of backcrosses that is necessary to recover a desirable seed-coat color.

\section{Acknowledgement}

This work was supported by grant No. (R 01-200000084) from the Korea Science and Engineering Foundation. IT182942, IT184172, T184178 and IT18425 were kindly supplied by the Gene Bank of the Rural Development Administration in Korea.

\section{Literature Cited}

Broich,S.L. and R.G.Parmer (1980) A cluster analysis of wild and domesticated soybean phenotypes. Euphytica 29: 23-32.

Broich,S.L. and R.G.Parmer (1981) Evolutionary studies of the soybean: The frequency and distribution of alleles among collections of Glycine max and G. soja of various origin. Euphytica 30: 55-64.

Carpenter,J.A. and W.R.Fehr (1986) Genetic variability for desirable agronomic traits in populations containing Glycine soja germplasm. Crop Sci. 26: 681-686.

Chung,G.H. and J.H.Kim (1990) Production of interspecific hybrids between Glycine max and G. tomentella through embryo culture. Euphytica 48: 97-101.

Gai,J.Y., W.R.Fehr and R.G.Palmer (1981) Performance of lines from four generations of a backcrossing program involving Glycine max and Glycine soja. Soybean Genet. Newsl. 8: 111-114.

Harlan,J.R. (1976) Genetic resources in wild relatives of crops. Crop Sci. 16: 329-333.

Hawkes, J.G. (1977) The importance of wild germplasm in plant breeding. Euphytica 26: 615-621.

Hymowitz,T. and C.A.Newell (1981) Taxonomy of the genus Glycine, domestication, and uses of soybean. Econ. Bot. 35: 272-288.

Hymowitz, T. and R.J.Singh (1987) Taxonomy and speciation. In "Soybeans: Improvement, Production and Uses" Wilcox, J.R. (ed.), $2^{\text {nd }}$ edn. Agronomy 16. p. 131-132.

Keim,P., T.C.Olson and R.C.Shoemaker (1988) A rapid protocol for isolating soybean DNA. Soybean Genet. Newsl. 15: 150-152.

Kim,K.U., T.D.Kang, J.H.Lee, I.J.Lee, D.H.Shin, Y.H.Hwang, S.U.Kim and H.M.Kim (2003) Physio-ecological characteristics of wild soybeans (Glycine soja) collected throughout Korea and their response to glyphosate. Korean J. Weed Sci. 23: 153-153 (in Korean with English summary).

LeRoy, A.R., W.R.Fehr and S.R.Cianzio (1991a) Introgression of genes for small size from Glycine soja into G. max. Crop Sci. 31: 693-697.

LeRoy,A.R., S.R.Cianzio and W.R.Fehr (1991b) Direct and indirect selection for small seed of soybean in temperate and tropical. Crop Sci. 31: 697-699.

Nei,M. and W.H.Li (1979) Mathematical model for studying genetic variation in terms of restriction endonucleases. Proc. Natl. Acad. Sci. USA 76: 5269-5273.

Park,D.H., K.M.Shim, Y.S.Lee, W.S.Ahn, J.H.Kang and N.S.Kim (1995) Evaluation of genetic diversity among the Glycine species using isozymes and RAPD. Korean J. Genetics 17: 157158.

Ting,C.L. (1946) Genetic studies on the wild and cultivated soybeans. J. Am. Soc. Agron. 38: 381-393.

Watanabe,K.N., M.Orrillo, S.Vega, J.P.T.Valkone, E.Pehu, A.Hurtado and S.D. Tanksley (1995) Overcoming crossing barriers between nontuber-bearing and tuber-bearing Solanum species: towards potato germplasm enhancement with a broad spectrum of solanaceous genetic resources. Genome 38: 27-35.

Watanabe,K.N. and M.Iwanaga (1999) Plant genetic resources and its global contribution. Plant Biotechnology 16: 7-13.

Woodworth,C.M. (1933) Genetics of the soybean. J. Am. Soc. Agron. 25: $36-51$.

Yang, G., H.Zheng, C.Han and F.Ji (1993) A preliminary study on protein and oil contents of wild soybean $(G$. soja) in Jilin Province. Soybean Genet. Newsl. 20: 35-38.

Yang, G., H.Zheng, C.Han, F.Ji and J.Hu (1994) The study on the techniques of usage of wild soybean in soybreeding. Soybean Genet. Newsl. 21: 27-31.

Yu,H. and Y.T.Kiang (1993) Genetic variation in South Korean natural populations of wild soybean (Glycine soja). Euphytica 69: 213-221. 